\title{
Correspondence
}

\section{SUCCESSFUL ELIMINATION OF FACTOR VIII INHIBITOR USING CYCLOSPORIN A}

Acquired Factor VIII (FVIII) deficiency is an uncommon but sometimes catastrophic autoimmune condition for which standard immune suppression, such as steroid or immunoglobulin infusion, is often insufficient to induce long-term remission (Dykes et al, 2001). A number of second-line therapies, such as cyclophosphamide, azathioprine and vincristine, have been used with varying success (Morrison \& Ludlam, 1995). Here, we describe the use of cyclosporin A in a patient in whom conventional treatments failed to eradicate the inhibitor. At present, only limited experience exists of its use in this setting (Pfliegler et al, 1989).

A 68-year-old woman with a 4-month history of easy bruising presented with life-threatening retropharyngeal haemorrhage. She had no significant past medical history, and medication consisted of aspirin and naproxen. Coagulation studies at presentation demonstrated a normal prothrombin time and fibrinogen activity but a prolonged activated partial thromboplastin time of $65 \mathrm{~s}$ (normal range 32-48 s). Factor assays confirmed a reduced FVIII coagulant activity (FVIII:C) at $1 \mathrm{i} \mu / \mathrm{dl}$. An inhibitor was detected and quantified at 54 Bethesda units (BU). von Willebrand factor activity and antigen were both within the normal range excluding acquired von Willebrand's disease.

Her initial treatment was with high-purity plasmaderived FVIII (Liberate, Scottish National Blood Transfusion Service), commencing at 20000 units twice daily, with prednisolone $60 \mathrm{mg}$ and high-dose intravenous immunoglobulin $(2 \mathrm{~g} / \mathrm{kg})$. Clinical response to treatment was excellent with no further haemorrhage. The patient's inhibitor titre remained detectable at 10-20 BU with FVIII:C remaining below $20 \mathrm{i} \mu / \mathrm{dl}$ over the succeeding months. The introduction of cyclophosphamide $50 \mathrm{mg}$ daily, 9 months after presentation, initially in conjunction with further prednisolone $(1 \mathrm{mg} / \mathrm{kg})$, rendered the inhibitor transiently undetectable, with FVIII:C peaking at $40 \mathrm{i} \mu / \mathrm{dl}$. However, with reduction of the prednisolone dose, the inhibitor returned, and the FVIII:C fell. After 9 months of treatment with cyclophosphamide, it was discontinued because of lack of a sustained response.

Approximately 28 months after presentation, cyclosporin A (CyA) was introduced at $100 \mathrm{mg}$ twice daily (3 $\mathrm{mg} / \mathrm{kg} / \mathrm{d})$, initially with prednisolone $(1 \mathrm{mg} / \mathrm{kg})$. A target trough plasma CyA concentration of 200-250 mg/l was achieved over 3 months with a dose of $175 \mathrm{mg}$ twice daily $(\approx 5 \mathrm{mg} / \mathrm{kg} / \mathrm{d})$, during which time the prednisolone was discontinued. The inhibitor titre fell and was undetectable 3 months after the commencement of CyA. The FVIII:C rose to within the normal range following disappearance of the inhibitor (Fig 1). After 14 months of therapy with CyA, and with FVIII:C levels remaining in the normal range, cyclosporine was reduced and stopped over a 4-month period. Ten months after cessation of all immunosuppressive therapy, the FVIII:C remains in the normal range with no detectable inhibitor.

Permanent eradication of inhibitor without the need for continued therapy is the ultimate aim of immunosuppressive treatment for acquired haemophilia. Initial reduction in inhibitor titre may be achieved with high-dose intravenous immunoglobulin and steroids; however, long-term clearance may not be achieved with this approach alone (Hay et al, 1996). Further options include cytotoxic regimens or immunosuppressant agents such as cyclosporine. As no



1024
Fig 1. Factor VIII and inhibitor levels. 
regime has been universally successful, and there have been no large immunomodulatory studies, no gold standard treatment has been established (Grunewald et al, 2001). Cytotoxic therapy may be associated with neutropenic sepsis; such cases have been reported in the treatment of acquired haemophilia (Lian et al, 1989). On the other hand CyA is well recognized as a precipitant of hypertension and renal impairment in addition to its anticipated immunosuppressive effects. The choice of treatment must then rest on the perceived risk of the options available.

This case demonstrates a lasting response attributed to CyA that was not achieved either by first-line therapy with steroid and intravenous immunoglobulin or by second-line therapy with cyclophosphamide. Although we cannot exclude spontaneous remission of the patient's FVIII inhibitor, the reduction in inhibitor titre commensurate with the introduction of CyA makes this unlikely. We conclude that CyA warrants consideration in patients refractory to firstline therapy for this rare but serious autoimmune disorder.

\author{
${ }^{1}$ Haemophilia Centre, Glasgow \\ Royal Infirmary, Glasgow, and \\ ${ }^{2}$ Department of Haematology, \\ Crosshouse Hospital, \\ Kilmarnock, UK. E-mail: \\ petermaclean@ \\ btopenworld.com
}

\section{REFERENCES}

Dykes, A.C., Walker, I.D., Lowe, G.D.O. \& Tait, R.C. (2001) Combined prednisolone and intravenous immunoglobulin treatment for acquired factor VIII inhibitors: a 2-year review. Haemophilia, 7, 160-163.

Grunewald, M., Beneke, H., Guthner, C., Germowitz, A., Brommer, A. \& Griesshammer, M. (2001) Acquired haemophilia: experiences with a standardized approach. Haemophilia, 7, 164-169.

Hay, C.R.M., Colvin, B.T., Ludlam, C.A., Hill, F.G.H. \& Preston, F.E. (1996) Recommendations for the treatment of factor VIII inhibitors: from the UK Haemophilia Centre Directors' Organisation Working Party. Blood Coagulation and Fibrinolysis, 7, 134-138.

Lian, E.C.Y., Larecada, A.F. \& Chiu, A.Y.Z. (1989) Combination immunosuppressive therapy after factor VIII infusion for acquired factor VIII inhibitor. Annals of Internal Medicine, 110, $774-778$.

Morrison, A.E. \& Ludlam, C.A. (1995) Acquired haemophilia and its management. British Journal of Haematology, 89, 231-236.

Pfliegler, G., Boda, Z., Harsfalvi, J., Flora-Nagy, M., Sari, B., Pecze, K. \& Rak, K. (1989) Cyclosporin treatment of a woman with acquired haemophilia due to factor VIIIC inhibitor. Postgraduate Medical Journal, 65, 400-402.

Keywords: acquired Factor VIII deficiency, Factor VIII inhibitor, cyclosporin A.

\section{MISCONCEPTIONS IN THALASSAEMIA DIAGNOSIS}

A full blood count was requested on a 2-day-old Pakistani boy. The child had mild anaemia with thalassaemic indices, blood film showed anisocytosis, poikilocytosis, target cells and polychromasia (Table I). High-performance liquid chromatography suggested a three alpha gene deletion with haemoglobin Barts $27 \cdot 7 \%$, haemoglobin F $44 \cdot 6 \%$ and haemoglobin A $19 \%$.

The mother's prenatal test results were normal (Table I). The father's results suggested alpha-thalassaemia trait or silent beta-thalassaemia trait (Table I). No other antenatal testing had been done as the fetus was not felt to be at risk of serious haemoglobinopathy.

Further questioning of the mother revealed she had had in vitro fertilization (IVF) using donated ova in another UK city. The donor, from Cyprus, had declared a family history

Table I. Haematology results of the patient and his parents.

\begin{tabular}{llllllll} 
& $\begin{array}{l}\mathrm{Hb} \\
(\mathrm{g} / \mathrm{dl})\end{array}$ & $\begin{array}{l}\mathrm{MCV} \\
(\mathrm{fl})\end{array}$ & $\begin{array}{l}\mathrm{MCH} \\
(\mathrm{pg})\end{array}$ & $\begin{array}{l}\mathrm{RBC} \\
\left(\times 10^{12} / \mathrm{l}\right)\end{array}$ & $\begin{array}{l}\mathrm{HbA2} 2 \\
(\%)\end{array}$ & $\begin{array}{l}\mathrm{HbF} \\
(\%)\end{array}$ & $\begin{array}{l}\text { Sickle } \\
\text { test }\end{array}$ \\
\hline Baby & $10 \cdot 8$ & 75 & $22 \cdot 9$ & $6 \cdot 03$ & & & \\
Father & $14 \cdot 3$ & $81 \cdot 5$ & $26 \cdot 9$ & $5 \cdot 31$ & $2 \cdot 2$ & $<1 \cdot 0$ & Negative \\
Mother & $13 \cdot 1$ & $82 \cdot 5$ & $28 \cdot 3$ & $4 \cdot 64$ & $2 \cdot 5$ & $<1 \cdot 0$ & Negative \\
Donor & $13 \cdot 2$ & 66 & $20 \cdot 5$ & $6 \cdot 44$ & $2 \cdot 9$ & $<1 \cdot 0$ & Negative \\
\hline
\end{tabular}

of thalassaemia at the IVF clinic and therefore underwent screening. This was reported as showing possible iron deficiency, and a card was issued stating that she had no significant haemoglobinopathy. Antenatal haemoglobinopathy screening for the biological mother during a previous pregnancy had also been reported as normal. Two further separate screens over a period of years had failed to comment on the significance of thalassaemic indices in the presence of a normal haemoglobin and $\mathrm{Hb} \mathrm{A} 2$.

DNA analysis showed the natural mother to have a Mediterranean $\alpha^{0}$ deletion $\left({ }^{\mathrm{MED}} / \alpha \alpha\right)$, the father a $3 \cdot 7-\mathrm{kb}$ $\alpha^{+}$-thalassaemia deletion $\left(-\alpha^{3 \cdot 7} / \alpha \alpha\right)$ and the baby haemoglobin $\mathrm{H}$ disease $\left(-\alpha^{3 \cdot 7} /{ }^{\mathrm{MED}}\right)$.

The donated ova from the same woman had also been used in other pregnancies, including a pregnancy using the donated ova and a sperm donor of Asian origin. This sperm donor had not had a haemoglobinopathy screen and had to be recalled.

This case highlights common problems in thalassaemia diagnosis, screening and reporting. Although guidelines for the laboratory diagnosis of haemoglobinopathies exist (British Committee for Standards in Haematology, General Haematology, 1998), there is currently no standardized reporting of results. The British Committee for Standards in Haematology (BCSH) guidelines state that screening is equally important in cases where pregnancy is the result of artificial insemination from a donor or in vitro fertilization, 
yet confidentiality issues mean that this information does not have to be passed on. Screening of both egg and semen donors is also recommended by the Human Fertilization and Embryology Authority, 2001), the British Andrology Society, 199) and the British Fertility Society (2000).

Although the majority of populations at risk of $\alpha$-thalassaemia have $\alpha^{+}$deletions, it is recommended that the $\alpha^{0}$-thalassaemia trait should be detected in prospective parents to predict the occurrence of haemoglobin Barts hydrops fetalis.

Mutations causing the $\alpha^{0}$-thalassaemia trait are found predominantly in south-east Asia, southern China $\left(-{ }^{\mathrm{SEA}} / \alpha \alpha\right.$, ${ }_{-} \mathrm{FIL} / \alpha \alpha$ and $\left.{ }^{\mathrm{THAI}} / \alpha \alpha\right)$ and the Mediterranean, particularly Cyprus, Turkey and Greece $\left(-{ }^{\mathrm{MED}} / \alpha \alpha\right)$.

DNA analysis should be done in patients from these ethnic groups with a $\mathrm{MCH}<25 \mathrm{pg}$ and where $\beta$ - and $\delta \beta$-thalassaemia and haemoglobin Lepore have been excluded.

In this case, the ethnic origin of the natural mother was not taken into account and the $\alpha^{0}$-thalassaemia trait therefore not considered. In such cases, it is necessary to add a statement that the ' $\alpha$-thalassaemia trait cannot be excluded' whether iron deficiency is present or not.

The National Health Service (NHS) plan is committed to a national, linked antenatal and neonatal screening programme for the haemoglobinopathies (NHS Plan, 2000).
We anticipate that this will give clear guidance as to which population groups are to be screened to achieve standardized reporting. These guidelines should include advice regarding the screening of semen and egg donors.

Department of Haematology, Royal Hallamshire Hospital,

Sheffield, UK. E-mail:

Josh.Wright@sth.nhs.uk

\author{
JoOst J. VAN VEEN \\ RICHARD KELLY \\ Claire Walker \\ JOSH WRIGHT
}

\section{REFERENCES}

British Andrology Society (1999) British Andrology Society guidelines for the screening of semen donors for donor insemination. Human Reproduction, 14, 1823-1826.

British Committee for Standards in Haematology, General Haematology (1998) The laboratory diagnosis of haemoglobinopathies. British Journal of Haematology, 101, 783-792.

British Fertility Society (2000) Recommendations for good practice on the screening of egg and embryo donors. Human Fertility, 3 , $162-165$.

Human Fertilisation and Embryology Authority (2001) Code of Practice, 5th edn. HFEA, London.

NHS Plan (2000) HMSO, London.

Keywords: haemoglobinopathy, antenatal screening, alpha-thalassaemia, in vitro fertilization. 